\title{
Moroccan clays for potential use as aluminosilicate precursors for geopolymer synthesis
}

\author{
Anass El Khomsi ${ }^{1,2 *}$, Ameni Ghaezouni ${ }^{2}$, Noureddine Idrissi kandri ${ }^{1}$, Abdelaziz Zerouale ${ }^{1}$ and Sylvie Rossignol ${ }^{2}$ \\ ${ }^{1}$ Laboratoire Signaux Systèmes \& Composants, Faculté des Sciences et Techniques B.P. 2202—Route d'Imouzzer, Fes, Morocco \\ ${ }^{2}$ IRCER, Ecole Nationale Supérieure de Céramique Industrielle, 12 rue Atlantis, 87068 Limoges Cedex, France
}

\begin{abstract}
Three Moroccan clays, denoted A1, A3 and A5, were sampled from the Fez region with the aim of potential use as aluminosilicate precursors for geopolymer synthesis. Each clay was subjected to calcination at $700{ }^{\circ} \mathrm{C}$ and analyzed using DTA/TG, grain size distribution measurements, XRD, and FTIR spectroscopy before and after heat treatment. The results showed that the three clays contain kaolinite in different proportions in addition to some associated minerals, such as quartz, hematite, calcite and dolomite. Heat treatment successfully activated the clay by the amorphization of kaolinite, which is essential for geopolymerization. Some other changes were observed in the associated minerals, especially carbonates, which partially or totally decomposed depending on the clay, while other minerals remained intact. The $S_{\text {BET }}$ and NBO values are in accordance with the degree of polymerization, and the obtention of consolidated materials is possible by alkali activation of the calcined clays.
\end{abstract}

\section{Introduction}

Morocco's natural mineral resources constitute an important part of the local economy and contribute to the development of the country [1]. Among these resources, clays are very abundant and have different compositions, which make them the raw material of choice for a large variety of uses.

The geographical distribution of these clay resources indicates a wide diversity and availability. For example, the quarries of the north are characterized by mineral assemblages containing various proportions of clay in addition to quartz and calcite, while those located in the center and the south (Fez, Meknes and Safi) are characterized by a dominant kaolinite content [2].

These latter clays have been widely used as the main raw material in many ceramic products, such as traditional pottery and bricks [3]. Recently, local research on these clay resources has led to ecological and innovative applications, such as the preparation of low-cost filtration membranes [4] and the removal by adsorption of heavy metals from wastewater [5-8].

More recently, the synthesis of new materials consolidated at room temperature, such as geopolymers, has been investigated [6,9-10]. These materials are three-dimensional amorphous aluminosilicate binders synthesized at room temperature by alkali activation of an aluminosilicate precursor such as metakaolin and/or calcined clay [11].
From an economic perspective, the use of natural impure clays minimizes the cost compared to that associated with metakaolin and valorizes an abundant natural resource [12]. All these characteristics have led to growing interest regarding geopolymer preparation from natural clays [13].

Natural clays contain, in addition to clayey minerals, some impurities, such as carbonates (calcite and dolomite), which are very common [14]. Thermal treatment induces transformations in several clay components, such as the dehydroxylation of kaolinite to metakaolin from $550{ }^{\circ} \mathrm{C}$ [15]. Impurities such as dolomite or calcite can also be affected by thermal activation of clays [16]. Calcite is transformed to calcium oxide from $650{ }^{\circ} \mathrm{C}$, whereas dolomite decomposes at $500{ }^{\circ} \mathrm{C}$ to magnesium oxide and calcite, which will decompose at higher temperatures of approximately $700^{\circ} \mathrm{C}$.

Some works have investigated the use of calcite or dolomite in geopolymer binders. The work of Aboulayt et al [17] has shown that calcite and dolomite, which are unreactive in alkaline media, act as fillers. In other cases, when calcium and magnesium are in the form of oxides $(\mathrm{CaO}$ and $\mathrm{MgO})$, they may react and be incorporated into the geopolymer network [18].

Some authors have investigated the possibility of using some Moroccan clays for geopolymer synthesis: S. Mabroum et al [19] successfully obtained alkaliactivated materials from chlorite-rich waste rock from a phosphate mine after thermal activation at $900{ }^{\circ} \mathrm{C}$ due to

* Corresponding author: anass.elkhomsi@usmba.ac.ma 
the high dehydroxylation temperature of this mineral. The use of clays containing various carbonates or different clays may be an opportunity for new industrial and technological uses that are eco-friendly.

The aim of this work was to demonstrate the physicochemical and structural properties of selected clays and the effect of thermal treatment on these materials for potential use as aluminosilicate precursors for geopolymer synthesis. The raw clays were crushed and calcined at well-defined temperatures.

The main characterization techniques used in this study are particle size distribution analysis, specific surface area analysis, thermal analysis, X-ray diffraction (XRD) and Fourier transform infrared (FTIR) spectroscopy.

\section{Materials and methods}

\subsection{Raw materials}

Three clays were selected from Fez city region. The first and second clays were sampled from areas surrounding Bhalil village, and the third clay was taken from a quarry called "Ben Jellik", which is widely exploited by artisans for traditional pottery and brickmaking.

The samples, marked A1, A3 and A5, were ground in two stages: first by an impact grinder to reduce the size of the grains to $500 \mu \mathrm{m}$ and then by using porcelain jars to obtain a finer particle size of less than $125 \mu \mathrm{m}$.

The ground clays were calcined at $700{ }^{\circ} \mathrm{C}$ for four hours with a fixed heating rate of $5^{\circ} \mathrm{C} / \mathrm{min}$ in an open-air kiln. The samples thus treated are denoted $\mathrm{AX}^{\mathrm{Tcal}}$, where $\mathrm{AX}$ denotes the Moroccan clay and Tcal is the calcination temperature. For example, a sample called $\mathrm{A} 3^{700}$ denotes A3 clay calcined at $700{ }^{\circ} \mathrm{C}$.

An activation solution was made of $\mathrm{KOH}$ pellets $(85.2 \%$ purity supplied by VWR) previously dissolved in potassium silicate solution $(\mathrm{Si} / \mathrm{K}=1.7$ supplied by ChemLab).

\subsection{Characterization techniques}

The chemical compositions of the samples were determined by X-ray fluorescence (XRF) using a Panalytical Zetium apparatus with a photon beam at 1 $\mathrm{kW}$. Pellets for analysis were prepared by mixing $1 \mathrm{~g}$ of powder with $10 \mathrm{~g}$ of a mixture of $99.5 \% \mathrm{Li}_{2} \mathrm{~B}_{4} \mathrm{O}_{7}$ and $0.5 \% \mathrm{LiI}$, melting the resulting mixture at a temperature of $1200{ }^{\circ} \mathrm{C}$, and pouring the material into a platinum mold to obtain the pellet.

Measurements of the $\mathrm{S}_{\mathrm{BET}}$ specific surface area were carried out using a Micromeritics ASAP 2020 under nitrogen gas at $-195.85^{\circ} \mathrm{C}$. The analysis was preceded by vacuum degassing of $1 \mathrm{~g}$ of sample at $200{ }^{\circ} \mathrm{C}$ for $9 \mathrm{~h}$. The particle size distribution was measured with a Horiba laser particle size analyzer. A laser beam passes through a glass cell with parallel surfaces, through which flows a suspension of water and powder. The analysis was carried out under ultrasound to avoid agglomeration of the particles to ensure accurate analysis.

The water demand $(\mu \mathrm{L} / \mathrm{g})$ corresponds to the quantity of water required to saturate one gram of powder.

XRD was carried out with a Bruker-D8 Advance with Bragg-Brentano geometry and a $\mathrm{Cu} \mathrm{K \alpha 2}$ detector. The analytical range was between 10 and 50 (2Ө) with a resolution of 0.02 and a residence time of $1.5 \mathrm{~s}$. Phases were identified with reference to Joint Committee Powder Diffraction Standard (JCPDS) cards.

FTIR spectra were acquired on a Thermo Fisher Scientific 380 (Nicolet) infrared spectrometer using the attenuated total reflectance (ATR) method.

The software was programmed to acquire spectra with 64 scans. In postprocessing, the contribution of $\mathrm{CO}_{2}$ was removed by linear adjustment of the spectra between 2280 and $2400 \mathrm{~cm}^{-1}$, and the baseline was corrected and normalized to allow comparison.

Thermogravimetric analysis (TGA) and differential scanning calorimetry (DSC) were performed in a $\mathrm{Pt}$ crucible between $30{ }^{\circ} \mathrm{C}$ and $800{ }^{\circ} \mathrm{C}$ using an SDT-Q600 apparatus. The heating rate was $5^{\circ} \mathrm{C} / \mathrm{min}$ under a dry air flow of $100 \mathrm{~mL} / \mathrm{min}$.

\section{Results and discussion}

\subsection{Physical, chemical and structural characterization of the raw samples}

Table 1. Nomenclature and physical properties of the raw

\begin{tabular}{|c|c|c|c|}
\multicolumn{4}{|c|}{ materials. } \\
Raw Clay & color & $\begin{array}{c}\text { SBET } \\
\left(\mathbf{m}^{\mathbf{2}} / \mathbf{g}\right) \pm \mathbf{5}\end{array}$ & $\begin{array}{c}\text { Wettability } \\
(\boldsymbol{\mu} \mathbf{L} / \mathbf{g}) \pm \mathbf{2 0}\end{array}$ \\
\hline $\mathbf{A 1}$ & Dark brown & 59 & 552 \\
\hline $\mathbf{A 3}^{\mathbf{2 5}}$ & Red & 46 & 593 \\
\hline $\mathbf{A 5}^{\mathbf{2 5}}$ & Light gray & 33 & 665 \\
\hline
\end{tabular}

Table 1 presents the results obtained for the three studied clays at $25{ }^{\circ} \mathrm{C}$ with respect to their visual appearance, specific surface area and wettability. Clay A1 has a slightly dark brown color, a specific surface area of 59 $\mathrm{m}^{2} / \mathrm{g}$ and a wettability of approximately $552 \mu \mathrm{L} / \mathrm{g}$.

Clay A3 has a slightly reddish color, a specific surface area of $46 \mathrm{~m}^{2} / \mathrm{g}$ and a wettability of approximately 593 $\mu \mathrm{L} / \mathrm{g}$. Finally, clay A5 has a brittle texture, a light gray color, a specific surface area of $33 \mathrm{~m}^{2} / \mathrm{g}$ and a wettability of approximately $665 \mu \mathrm{L} / \mathrm{g}$. These data are in the same range as the results of other studies on clay minerals [2022]. 
(a)

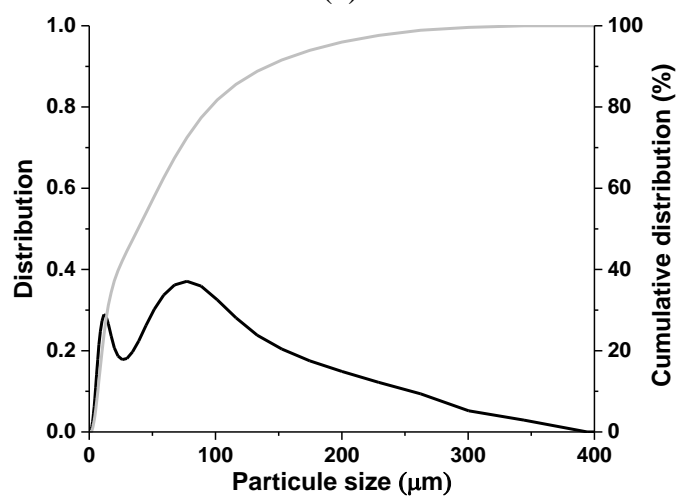

(b)

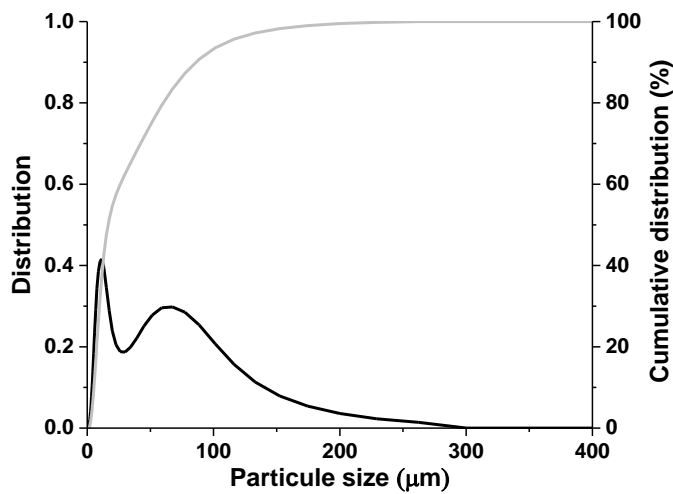

(c)

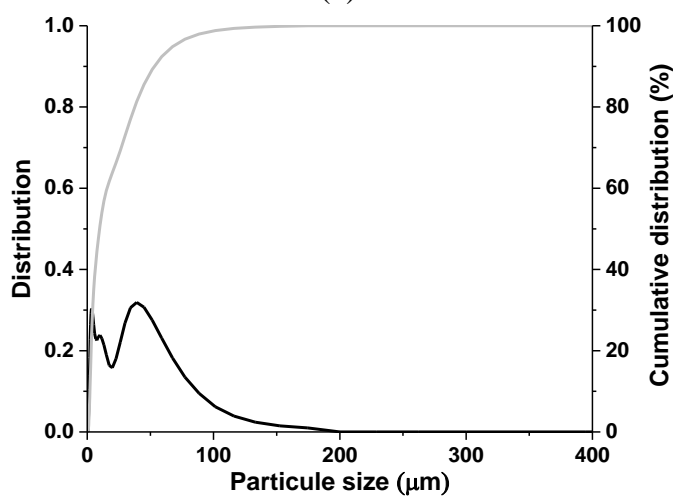

Fig. 1. Particles size distribution curves for, (a) $\mathrm{A} 1^{25}$, (b) $\mathrm{A} 3^{25}$, (c) $\mathrm{A} 5^{25}$, (一 distribution) (一 cumulative distribution).

The particle size distribution analysis of the three crushed clays reveals variable distribution curves (Figure 1). For sample $\mathrm{A} 1^{25}$, the distribution curve (Figure 1a) shows the existence of three populations of grain sizes, a first population smaller than $70 \mu \mathrm{m}$, a second centered at $77 \mu \mathrm{m}$ and a third in the range of 150 to $380 \mu \mathrm{m}$.

The distribution curve of the $\mathrm{A} 3^{25}$ clay (Figure 1b) shows the existence of two populations of fine particles centered at $11 \mu \mathrm{m}$ and between 50 and $200 \mu \mathrm{m}$. Clay $\mathrm{A} 5^{25}$ (Figure 1c) has a distribution characterized by two populations of grain sizes: fine particles are centered at $9 \mu \mathrm{m}$, and larger particles are centered at $42 \mu \mathrm{m}$.

These obtained values explain the measured wettability results; in fact, the two parameters are proportional: fine particles need a larger amount of water to be saturated than coarse grains.
Table 2. Chemical composition of the raw clays used.

\begin{tabular}{|c|c|c|c|}
\hline \multirow{2}{*}{ Clay } & \multicolumn{3}{|c|}{ Molar ratio } \\
\cline { 2 - 4 } & $\mathbf{S i} / \mathbf{A l}$ & $\mathbf{C a} / \mathbf{A l}$ & $\mathbf{M g} / \mathbf{A l}$ \\
\hline $\mathbf{A 1}$ & 1.84 & 4.39 & 2.15 \\
\hline $\mathbf{A 3}^{25}$ & 3.03 & 0.98 & 0.64 \\
\hline $\mathbf{A 5}^{25}$ & 2.61 & 0.99 & 0.32 \\
\hline
\end{tabular}

The chemical compositions of the studied samples, obtained from XRF analysis, made it possible to deduce the values of the molar ratios $(\mathrm{Si} / \mathrm{Al}, \mathrm{Ca} / \mathrm{Al}$ and $\mathrm{Mg} / \mathrm{Al})$ for each clay (Table 2). Clay A1 has a Si/Al molar ratio of 1.84 , which indicates that silica is more abundant than aluminum, and therefore, the presence of 2:1-type clay minerals is possible [23]. The $\mathrm{Ca} / \mathrm{Al}$ molar ratio is 4.39 , indicating a high calcium content, and the $\mathrm{Mg} / \mathrm{Al}$ molar ratio is 2.15 , which is relatively high. Sample A3 is characterized by less aluminum than silica compared to the clay A1 $(\mathrm{Si} / \mathrm{Al}=3.03)$, also the calcium and magnesium contents are lower $(\mathrm{Ca} / \mathrm{Al}=0.98$ and $\mathrm{Mg} / \mathrm{Al}$ $=0.64)$. Sample A5 has the lowest molar ratio of $\mathrm{Si} / \mathrm{Al}$, with a value of 2.61, which may suggest the presence of 2:1-type clay minerals. The proportion of calcium in clay $\mathrm{A} 5(\mathrm{Ca} / \mathrm{Al}=0.99)$ is closer to that of $\mathrm{A} 3$, while the molar ratio $\mathrm{Mg} / \mathrm{Al}(=0.32)$ is lower.

(a)

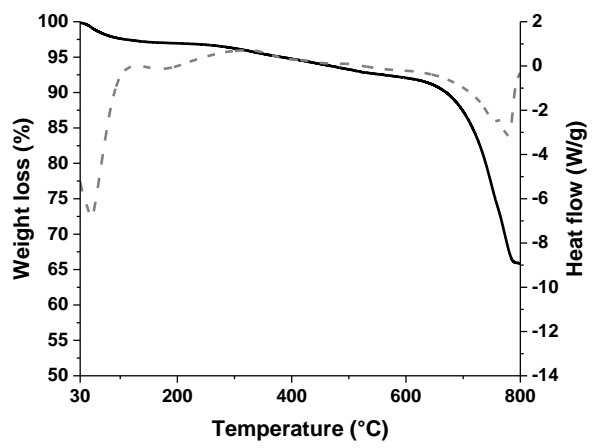

(b)

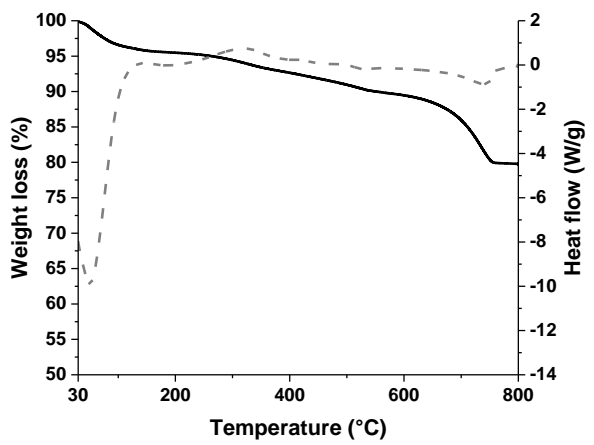

(c)

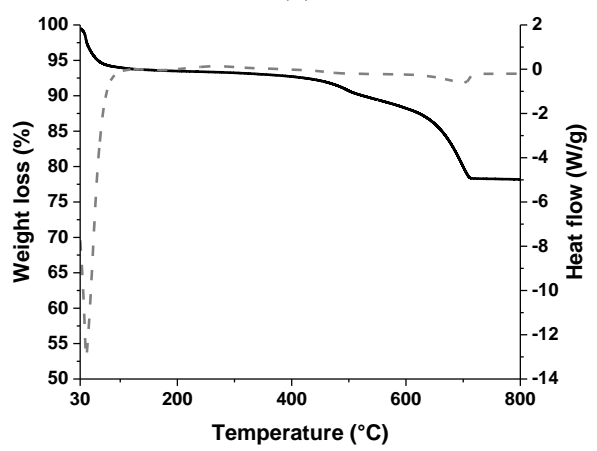

Fig. 2. TGA curves of the (a) $\mathrm{A} 1^{25}$, (b) $\mathrm{A} 3^{25}$ and (c) $\mathrm{A} 5^{25}$, (weight loss) (--- heat flow). 
The TGA thermogram of clay A1 reveals (Figure 2a) a first weight loss of $3 \%$ between 30 and $200{ }^{\circ} \mathrm{C}$ attributed to physisorbed water [16], while the second weight loss of $2.2 \%$ from 200 to $400{ }^{\circ} \mathrm{C}$ could be caused by the loss of water due to the dehydration of $\mathrm{FeOOH}$ [24]. Then, an endothermic phenomenon between 400 and $600{ }^{\circ} \mathrm{C}$, accompanied by a loss of $2.7 \%$, can be attributed to the dehydroxylation of kaolinite [25]. The temperature range of 600 to $800{ }^{\circ} \mathrm{C}$ is marked by two endothermic phenomena, the first possibly being due to the decomposition of dolomite and the second to the decomposition of calcium carbonate [25]. For clay A3 (Figure 2b), the same weight losses are noted, but with slight differences in value: 4.5, 2.8, 3.1 and 9.7\% losses are attributed to physisorbed water, dehydration of $\mathrm{FeOOH}$, dehydroxylation of kaolinite and decomposition of carbonates, respectively. The same observation was made for clay A5 (Figure 2c), and the weight loss values are $6.5,0.8,4.5$ and $10 \%$ for physisorbed water, dehydration of $\mathrm{FeOOH}$, dehydroxylation of kaolinite and decomposition of carbonates, respectively.

Table 3. Kaolinite and carbonate amount calculated from the weight losses deduced from TGA analysis.

\begin{tabular}{|c|c|c|}
\hline Clay & Kaolinite (Wt \%) & Carbonates (Wt \%) \\
\hline $\mathbf{A 1}^{\mathbf{2 5}}$ & 27 & 32 \\
\hline $\mathbf{A 3}^{\mathbf{2 5}}$ & 28 & 9 \\
\hline $\mathbf{A 5}^{\mathbf{2 5}}$ & 22 & 27 \\
\hline
\end{tabular}

The TGA results made it possible to evaluate the percentages of carbonates and kaolinite contained in each clay (Table 3 ). Thus, clay A3 contains the highest kaolinite content with a percentage of $27.9 \%$, while clays A1 and A5 contain 27.2 and 21.5\%, respectively. On the other hand, clay A1 has a higher carbonate content $(32 \%)$, while clay A3 has a low content of this mineral $(8.5 \%)$.

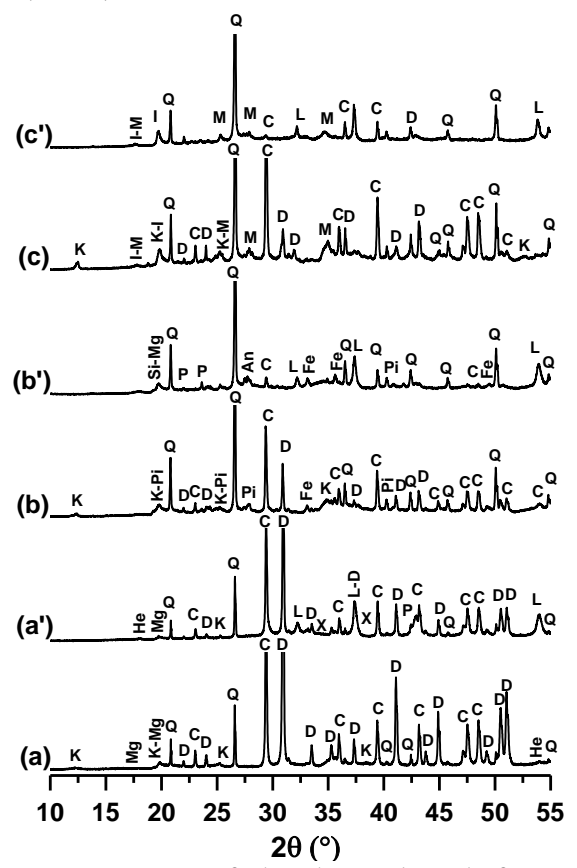

Fig. 3. XRD patterns of the three clays before and after calcination, with (a) $\mathrm{A} 1^{25}$, (a') $\mathrm{A} 1^{700}$, (b) $\mathrm{A} 3^{25}$, (b') $\mathrm{A} 3^{700}$, and (c) $\mathrm{A} 5^{25}$ and (c') A5 ${ }^{700}$. JCPDS files (Q: Quartz (01-0891961) ; K: Kaolinite (00-006-0221); I: Illite (04-017-0523);
M: Muscovite(00-034-0175); Mg : Magnesium oxyde hydroxide (04-014-8449); Pi : Pigeonite (01-076-2962); C: calcite (00-047-1743); D: Dolomite (04-011-9830); Fe : Hematite (01-077-9927) ; L: Lime (00-037-1497) ; P : Periclase (04-010-4039) ; An :Anorthite, sodian (00-0181202) ; SiMg: potassium magnesium silicate (JCPDS 00-0400021)).

To confirm and complete the TGA results, the structural properties of the studied clays were highlighted by the XRD and FTIR data (Figures 3 and 4). The diffractogram of sample $\mathrm{A} 1^{25}$ (Figure 2a) indicates the presence of kaolinite, hematite, quartz, calcite and dolomite. Clay $\mathrm{A} 3^{25}$ is also characterized by these same phases, as well as pigeonite. The third clay, $\mathrm{A} 5^{25}$ (Figure $3 \mathrm{c}$ ), contains three clayey phases, kaolinite, illite and muscovite, in addition to associated minerals such as quartz, dolomite and calcite.
(A)

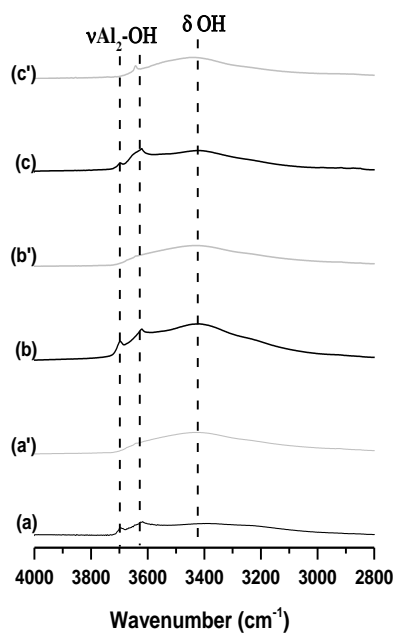

(B)

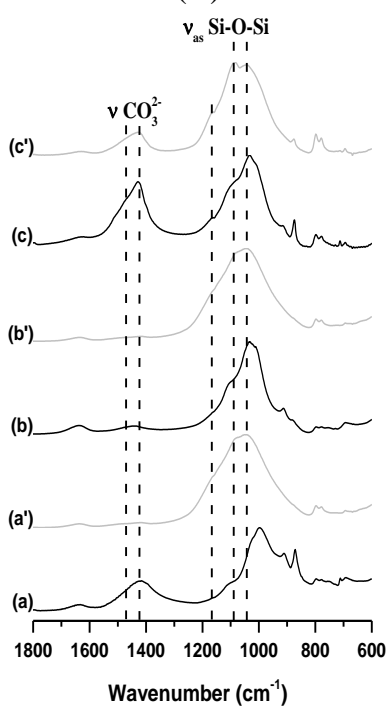

Fig. 4. FTIR spectra of the raw (black line) and calcined (grey line) of the three clay, (A) from 4000 to $2800 \mathrm{~cm}^{-1}$, and (B) from 1800 to $600 \mathrm{~cm}^{-1}$, with (a) $\mathrm{A}^{25}$, (a') $\mathrm{A}^{700}$, (b) $\mathrm{A}^{25}$, (b') $\mathrm{A} 3^{700}$, (c) $\mathrm{A} 5^{25}$ and (c') $\mathrm{A} 5^{700}$

The FTIR spectrum of clay A $1^{25}$ (Figure 4a) displays bands at 3697, 3672, 3649 and $3621 \mathrm{~cm}^{-1}$, which are attributed to kaolinite [26]. In addition, the bands at 3660 and $3640 \mathrm{~cm}^{-1}$ are related to illite [27]. The bands located at 1106,1026 , and $1004 \mathrm{~cm}^{-1}$ are related to Si$\mathrm{O}-\mathrm{Si}$ bonds characteristic of the kaolinite phase. The bands at 911 and $933 \mathrm{~cm}-1$ are related to Al-OH [28]. The same is true for quartz, with doublet positions at 797 and $778 \mathrm{~cm}^{-1}$ [29]. The band at $1620 \mathrm{~cm}^{-1}$ is attributed to water deformation [30]. The other contributions are due to carbonate species, such as calcite at 2500, 1416, 872 and $711 \mathrm{~cm}^{-1}[31]$. The spectrum of sample $\mathrm{A} 3^{25}$ (Figure $4 \mathrm{~b})$ shows the same contributions of kaolinite, quartz and water. Other bands at 1800,1435 and $730 \mathrm{~cm}^{-1}$ are due to carbonate species in dolomite [32], other bands at 873 and $711 \mathrm{~cm}^{-1}$ indicate the presence of calcite, while the weak band at $\mathrm{cm}^{-1}$ is related to dolomite. The spectrum of clay $\mathrm{A} 5^{25}$ (Figure $4 \mathrm{c}$ ) reveals the same bands as those observed for $\mathrm{A}^{25}$, but the intensity of the carbonate bands at $1417 \mathrm{~cm}^{-1}$ is greater than that of $\mathrm{A} 3^{25}$. Based on this information, kaolinite, which is an 
essential compound for geopolymer synthesis is present in the three collected clays, which enables these clays to be used as precursors for geopolymer formation.

\subsection{Effect of thermal treatment}

The effect of thermal treatment at $700{ }^{\circ} \mathrm{C}$ on the three clays was investigated by XRD (Figure 3) and FTIR spectroscopy (Figure 4). The diffractogram of $\mathrm{A} 1^{700}$ (Figure $3\left(\mathrm{a}^{\prime}\right)$ ) shows reflections associated with quartz $\left(\mathrm{SiO}_{2}\right)$, hematite $\left(\mathrm{Fe}_{2} \mathrm{O}_{3}\right)$ and magnesium oxide hydroxide even after calcination, which means that the crystal structures of these minerals withstands the calcination temperature. The main difference is the disappearance of kaolinite peaks, indicating a transformation into amorphous metakaolin [33]. Indeed, the dehydroxylation of kaolinite begins at $450{ }^{\circ} \mathrm{C}$, giving rise to the formation of amorphous metakaolin. New phases appear, such as lime and magnesium oxide, resulting from the decomposition of calcite and dolomite, although some reflections of calcite and dolomite are still visible, which indicates incomplete decomposition. However, their characteristics have changed, revealing a certain disorder in the structure [34]. The diffractogram of clay A $3^{700}$ (Figure 3 (b')) reveals similar changes to those observed for $\mathrm{A} 1^{700}$, in addition to the total disappearance of dolomite peaks, which indicates the total decomposition of the dolomite crystal structure. In fact, some studies have shown that the rate of decomposition of carbonate species is linked to their crystal size, and it has been observed that large crystals decompose more than small ones [35]. The diffractogram of clay $\mathrm{A5}^{700}$ (Figure $3\left(\mathrm{c}^{\prime}\right)$ ) is characterized by partial decomposition of calcite and dolomite, as observed for clay $\mathrm{A}^{700}$, while phases such as illite and muscovite withstood the calcination temperature. The obtained FTIR spectra (Figure 4) clearly reveal the effect of heat treatment on the compounds constituting the three studied clays. Sample $\mathrm{A} 1^{700}$ (Figure $4 \mathrm{a}$ ') is characterized by the disappearance of kaolinite bands ( 3695 and $3617 \mathrm{~cm}^{-1}$ ) caused by the transformation of kaolinite into metakaolin [36]. The intensities of the vibration bands of water at $1600 \mathrm{~cm}^{-1}$ and calcite at $1416 \mathrm{~cm}^{-1}$ decreased due to the departure of physical water and the partial decomposition of calcite, respectively [35]. The amorphization of kaolinite is indicated by the enlargement of the band at approximately $1045 \mathrm{~cm}^{-1}$, which corresponds to the stretching of Si-O-Si and Si-O-Al bonds in the formed metakaolin network [37]. The spectrum of sample $\mathrm{A} 3^{700}$ (Figure $4 \mathrm{~b}$ ') shows similar changes, and the bands corresponding to kaolinite and to water either disappeared or decreased in intensity, as observed in the case of $\mathrm{Al}^{700}$. The carbonate bands moved towards lower frequencies $\left(1416 \mathrm{~cm}^{-1}\right)$, indicating the decomposition of dolomite and the persistence of calcite. The spectrum of clay $\mathrm{A} 5^{700}$ after treatment (Figure $4 \mathrm{c}^{\prime}$ ) indicates the disappearance of the bands of kaolinite and water, and the vibration band of illite remains visible at $3640 \mathrm{~cm}^{-1}$, which is logical; in fact, the calcination temperature of $700{ }^{\circ} \mathrm{C}$ does not allow dehydroxylation of illite. For the carbonate bands, a decrease in intensity is observed.

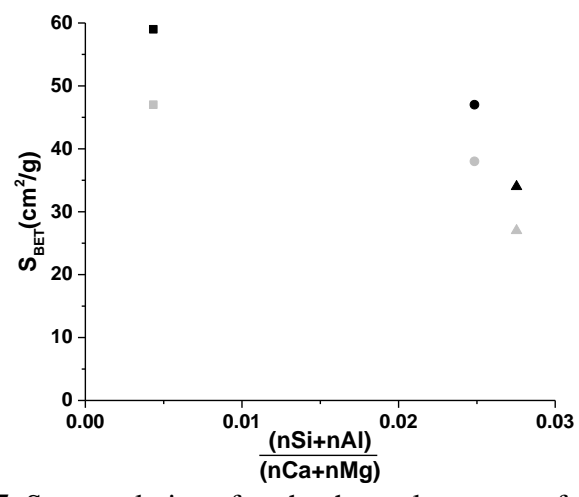

Fig. 5. S $\mathrm{S}_{\text {BET }}$ evolution after the thermal treatment for the three clays, (! ) A1, (, ) A3 and (7) A5, (! raw) and (! thermally treated).

The specific surface areas of the three clays before and after heat treatment are reported as a function of the molar ratio $\frac{(n S i+n A l)}{(n C a+n M g)}$ (Figure 5).

The three clays studied present a decrease in specific surface area after calcination. The $\mathrm{S}_{\mathrm{BET}}$ values evolved from 60 to $46 \mathrm{~m}^{2} / \mathrm{g}$ for $\mathrm{A} 1$, from 46 to $35 \mathrm{~m}^{2} / \mathrm{g}$ for $\mathrm{A} 3$ and from 33 to $26 \mathrm{~m}^{2} / \mathrm{g}$ for A5. This general decrease in $\mathrm{S}_{\mathrm{BET}}$ values could be explained by amorphization and transformation during thermal treatment [38]. On the other hand, when the amount of aluminum, calcium or magnesium increases, $\mathrm{S}_{\mathrm{BET}}$ decreases due to the presence of kaolin and carbonates, characterized by a low specific surface area [39-40]. In addition, the contributions of the FTIR bands in the range of 1200$920 \mathrm{~cm}^{-1}\left(v_{\mathrm{s}} \mathrm{Si}-\mathrm{O}-\mathrm{Si} ; \mathrm{Q}^{\mathrm{n}}\right)$ permit the determination of the non-bridging oxygens $(\mathrm{NBO})$ value $(\mathrm{NBO}=(3 \times \mathrm{Q} 1+$ $2 * \mathrm{Q} 2+\mathrm{Q} 3) / 100$ ), which provides information about the degree of depolymerization and degree of the amorphous phase [39]. The NBO values are 1.31, 1.30 and 0.81 for clays $\mathrm{A} 1, \mathrm{~A} 3$ and $\mathrm{A} 5$, respectively. Consequently, the A5 clays appear to be less depolymerized, in agreement with its low $\mathrm{S}_{\mathrm{BET}}$ values, whereas $\mathrm{A} 1$ and $\mathrm{A} 3$ are more polymerized.

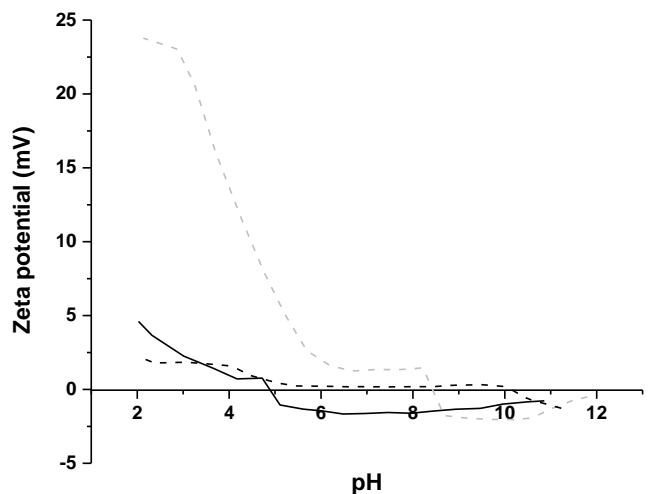

Fig. 6. Zeta potential curves as function of $\mathrm{pH}$ of the calcined clays $\mathrm{A} 1^{700}, \mathrm{~A} 3^{700}$ and $\mathrm{A} 5^{700}$.

The behavior of the three calcined clays in aqueous solution is an important information that impacts the workability of the slurry made of this clays, the dispersion or agglomeration depends on the surface charges of particles [41]. To determine this parameter, Zeta potential measurement was performed on calcined clay-water suspension within the $\mathrm{pH}$ range (2-11). The 
magnitude of zeta potential indicates the electrostatic repulsion between neighboring, similarly charged particles, a higher zeta potential in absolute value indicates a better stability, and less aggregation and precipitation. The obtained curves of Zeta potential vs $\mathrm{pH}$ for the three calcined clays are plotted in (Figure 6). Regardless of the clay the zeta potential decrease disproportionately to the $\mathrm{pH}$ value; in acidic $\mathrm{pH}$ the zeta potential is positive and turn to negative values in basic $\mathrm{pH}$. The calcined clay $\mathrm{A} 1^{700}$, shows the lowest zeta potential $(2 \mathrm{mV})$ in acidic medium, and reach the point of zero charge (pzc) from $\mathrm{pH}=5$ until $\mathrm{pH}=10.5$ where a plateau is observed, above $\mathrm{pH} 10.5$ the zeta potential turn to negative value and reach $(-2 \mathrm{mV})$ at $\mathrm{pH} 11$. The second clay $\mathrm{A} 3^{700}$ shows the same tendency with different values of surface charges, in acidic $\mathrm{pH}$, Zeta potential is higher than $\mathrm{A} 1^{700}(4.6 \mathrm{mV})$, the (pzc) is also reached at $\mathrm{pH} 5$, and turns to negative values $(-1.1 \mathrm{mV})$ above that $\mathrm{pH}$. The clay $\mathrm{A} 5^{700}$ shows different zeta potential variation compared to $\mathrm{A} 1^{700}$ and $\mathrm{A} 3^{700}$, at $\mathrm{pH} 2$ the surface charge value is $(24 \mathrm{mV})$ which is the highest value of the three clays, than the (pzc) is reached at higher $\mathrm{pH}$ (8.2), after that, the surface charge become negative $(-2 \mathrm{mV})$ and increase slightly to $(-1.3 \mathrm{mV})$ at pH 11.

These results indicates that $\mathrm{A} 1^{700}$ and $\mathrm{A} 3^{700}$ both have low surface charge in absolute value whatever the $\mathrm{pH}$, and therefore these clays will tend to agglomerate and precipitate. In the other hand $\mathrm{A} 5^{700}$ exhibits a high surface charge in acidic $\mathrm{pH}$ indicating a greater dispersion, while in basic $\mathrm{pH}$, the surface charge is low indicating a weak stability of the suspension. The variation of zeta potential as function of $\mathrm{pH}$ can be explained by the heterogeneity in term of mineralogical composition. In fact, the three calcined clays contain phyllosilicates, metakaolin, quartz and carbonates in different proportions. It is well known in literature that the surface charge of phyllosilicate like illite and muscovite is negative in $\mathrm{pH}$ values above 2.5 [42-43]. On the other hand, metakaolin has a positive charge in acidic $\mathrm{pH}$ due to the positively charged aluminates groups, and after the (pzc) at $\mathrm{pH}(4-5)$ the negative charge is predominant due to hydroxyl groups that attach to aluminate dehydroxylated sites [44]. Moreover, for the calcium carbonates, the surface charge is positive [45]. The simultaneous presence of opposite charges from these minerals, results on a low or almost neutral Zeta potential values in basic $\mathrm{pH}$. On the other side, the positive values in acidic medium are caused by the accumulation of the metakaolin [46] and carbonates positives charges. It was observed that the clay $\mathrm{A} 5^{700}$ exhibits the higher surface charge in basic medium; this could be explained by the high carbonate content $(32 \%)$ in addition to metakaolin, and the presence of $\mathrm{CaO}$ resulting from the calcination that contribute to the increase of zeta potential into higher positive sign [46]. A slight increase in zeta potential after $\mathrm{pH} 11$ for the three clays is also observed, which could be explained by alkali-activation of the metakaolin phase in basic medium [1]. These data indicate that the clays will agglomerate, especially in basic $\mathrm{pH}$ values, and therefore the addition of a dispersant or a negatively charged compound like metakaolin will reduce the zeta potential and lead to a better stability. (a)

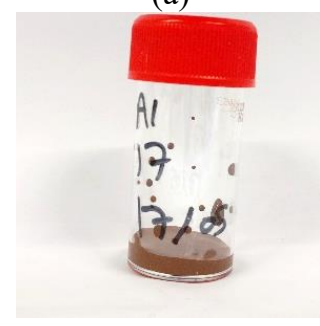

(b)

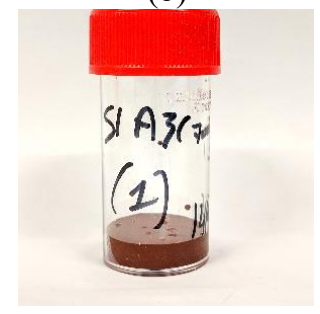

(c)

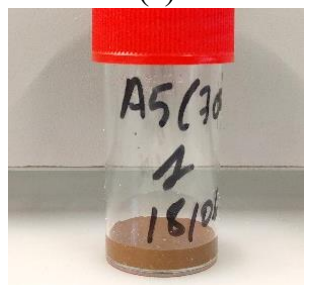

Fig. 7. Pictures of the consolidated materials aged of 24 hours based on (a) clay $\mathrm{A} 1^{700}$, (b) clay $\mathrm{A} 3^{700}$ and (c) clay A $5^{700}$.

To confirm the usability of the three calcined clay, an alkaline potassium silicate solution was added to each clay and a consolidation state was observed in the three cases after 24 hours (Figure 7), which shows that these clays are suitable for geopolymer synthesis, the study of these materials are reported in another publication [47].

\section{Conclusion}

The objective of this study was to elucidate the physicochemical and structural properties of three clays from the Fez region of Morocco. This analysis was conducted in view of the potential future use of these natural clays as raw materials in the synthesis of geopolymers. The obtained results reveal the presence of kaolinite in the three selected clays with varying contents. Other associated minerals, such as muscovite, illite, calcite and dolomite, are also present in small amounts. The calcination at $700{ }^{\circ} \mathrm{C}$ of these samples induced, in addition to a reduction in specific surface area and the transformation of kaolinite into metakaolin. On the other hand, the calcination process not or partially affected certain other minerals, such as illite, muscovite and carbonate compounds. The degree of polymerization deduced from the NBO data showed a correlation with the $\mathrm{S}_{\mathrm{BET}}$ value [48]. The zeta potential measurements showed a neutral charge, which indicates a low stability of the slurry especially at alkaline $\mathrm{pH}$ where the metakaolin starts to dissolve due to the alkaliactivation of this mineral.

The preliminary test showed that it is possible to obtain consolidated materials. From this perspective, it will be interesting to test these Moroccan clays for the preparation of geopolymers and study the impact of their compositions on the final properties of the resulting geopolymers. 


\section{References}

1. P. Billaux et G. Bryssine, Cahiers de la recherche agronomique, 1, 59-101 (1967)

2. M. El Ouahabi, L. Daoudi, N. Fagel, Clay Miner, 49, 35-51 (2014).

3. M. Monsif, R. Sylvie, F. Allali, A. Zerouale, N. Idrissi Kandri, J. Emmanuel, T. Sergio, B. Roberta, J. Mater. Environ. Sci, 8, 2704-2721

4. A. Ismaili M'hamdi, N. Idrissi Kandri, A. Zerouale, J. Mater. Environ. Sci. 8, 2816-2831 (2017)

5. H. Ouaddari, A.Karim, B. Achiou, S. Saja, A. Aaddane, J. Bennazha, I. El Amrani El Hassani, M. Ouammou, A. Albizane, J. Environ. Chem. Eng. 7, 103-268 (2019)

6. H. Es-sahbany, M.Berradi, S. Nkhili, R. Hsissou, M. Allaoui, M. Loutfi, D. Bassir, M. Belfaquir, M. S. El Youbi, Mater. Today:. Proc. 13, 866-875, (2019)

7. R.K. Preethi, B.V. Venkatarama Reddy, Constr. Build. Mater., 257, 119563 (2020)

8. N. Kamoun, F. Jamoussi, M.A. Rodriguez, Boletin de la Sociedad Espanola de Ceramica y Vidrio, 59, 25-30 (2020)

9. N. El Baraka, A. Laknifli, N. Saffaj, M. Addich, A. Ait Taleb, R. Mamouni, A. Fatni et M. Ait Baih, E3S Web of Conferences, 150, 01007 (2020)

10. O. Biel, P. Rozek, P. Florek, W. Mozgawa et M. Krol, Crystals, 10, 268 (2020)

11. S. Mkaouar, W. Maherzi, P. Pizette, H. Zaitan et M. Benzina, J. Afric. E. Sci, 160, 103620, (2019)

12. J. Davidovits, Geopolymer Institute, Saint-Quentin, France, (5 th $\left.^{\text {Ed }}\right), 1-38$ (2008)

13. P. Choeycharo, W. Sornlar, W. Shongkittikul, et A. Wannagon, chiang mai j. sci, 46, 1234-1248 (2019)

14. C. Shi, L. Chong, X. Hu, et X. Liu, indian concr. J, 89, 49-57 (2015)

15. A. Marsh, A. Heath, P. Patureau, P. Evernden, et P. Walker, Constr. build. Mater, 229 (2019)

16. E. Gasparini, S. C.Tarantino, P. Ghigna, M. PiaRiccardi, E. I.Cedillo-González, C. Siligardi, M. Zema, appl. clay sci, 80-81, 417-425 (2013)

17. P. Engler, M. W. Santana, M. L. Mittleman, D. Balazs, cheminform, 20, 3-8 (1989)

18. A. Aboulayt, M. Riahi, M. Ouazzani Touhami, H. Hannache, M. Gomina, et R. Moussa, Adv. Pow. Tech, 28, 2393-2401 (2017)

19. A. Gharzouni, L. Ouamara, I. Sobrados, et S. Rossignol, J. of Non-Cryst. Sol, 484, 14-25 (2018)

20. S. Mabroum, A. Aboulayt, Y. Taha, M. Benzaazoua, N. Semlal, et R. Hakkou, J of clea. Prod, 261 (2020)

21. J. Peyne, A. Gharzouni, I. Sobrados, et S. Rossignol, appl. clay sci, 160, 290-298 (2018)

22. M.U. Shafiq, H.K. Ben Mahmud, M.K. Zahoor, A.S.A. Shahid, R. Rezaee et M. Arif, J. of Pet. Exp and Prod. Tech, 9, 2793-2809 (2019)
23. D. Al Mahrouq, J. Vinogradov, M.D. Jackson, Adv. Colloid Interface Sci., 240, 60-76 (2017)

24. S. W. Bailey, Clay Miner., 15, 85-93 (1980)

25. S. Xiaowei and J. Boily, J.of Phy Chem, 120, 6249 6257 (2016)

26. C. Biellmann, Thesis, Université Rennes 1, (1993)

27. H.VanOlphen, J.J. Fripiat, Pergamon Press. Oxford, 49, 243-284 (1979)

28. J. Madéjova, vib. Spectrosc, 31, 1-10 (2003)

29. A.M. Qtaitat, N.I. Al-Trawneh, Spectrochimica Acta Part A, 61, 1519-1523 (2005)

30. S. Kramar, J. Lux, MTAEC9 49, 503, (2015)

31. S.M. Francis, W.E. Stephens, N.V. Richardson, Environmental Health, 8, (2009)

32. S. Gunasekara, G. Anbalagan, et S. Pandi, J.Raman Spectrosc, 37, 892-899 (2006)

33. C.K Huang, P. F. Kerr, Am. Mineral, 45, 11-324 (1960)

34. M. Glid, I. Sobrados, H.B. Rhaiem, J. Sanz, et A.B. H. Amara, Ceram. Int, 43, 12641-12650 (2017)

35. C.Ionescu, V. Hoeck, C. Gruian, V. Simo, Appl. Clay Sci, 97-98, 138-145 (2014)

36. O. Sivrikaya, Ironmaking \& Steelmaking, 45, (2017)

37. A. Elimbi, H.K. Tchakoute, D. Njopwouo, Constr. Build. Mater., 25, 2805-2812 (2011)

38. A. Sathonsaow, P. Chindaprasirt and K. Pimraksa, j. hazard. mater, 168, 44-50 (2009)

39. Q. Weia, D. Wang, S. Zhang et C. Chen, J. Alloys Compd., 325, 223-229 (2001)

40. W.J. Malfait, W.E. Halter, Y. Morizet, B.H. Meier, R. Verel, Geochim. Cosmochim. Ac, 71, 60026018 (2007)

41. E.C Ruvolo Jr., H.L. Bellinetti, M.A. Aegerter, J. Non-Cryst. Solids, 121, 244-249 (1990)

42. Wei Chen, Qiu Li, Zhonghe Shui and Bo Yuan, Front. Mater., 60 (2019)

43. S.A. Hussain, S. Ahignde Demigrcig, Gu. Lhan O Zbayog Lu, J. Colloid Interface Sci., 184, 535-541 (1996)

44. R. Sposito, N. Beuntner, K.C. Thienel, Cem. Concr. Compos., 110, 103594 (2020)

45. N. Mladenović, L. Kljajević, S. Nenadović, M. Ivanović, B. Čalija, J. Gulicovski, K. Trivunac, J. Inorg. Organomet. Polym Mater., 30, 554-563 (2020)

46. M. Mahmoudpour, P. Pourafshary, J. Pet. Sci. Eng., 196, 107662 (2021)

47. W. Ruikun, L. Jianzhong, Y. Yujie, Z. Junhu, C. Kefa, Sci. Total Environ., 456-457, 9-16 (2013)

48. A. El Khomsi, A. Gharzouni, N. Idrissi Kandri, A. Zeouale, S. Rossignol, Cer. Modren. Tech, 2 (2020)

49. C. He, B. Osbaeck, E. Makovicky, Cem. Concr. Res., 25, 1691-1702 (1995) 